\title{
Importance of surface oxide for the tribology of a Zr-based metallic glass
}

\author{
S. J. KANG ${ }^{1,2, \dagger}$ K. T. RITTGEN ${ }^{1,3}$, S. G. KWAN ${ }^{2}$, H. W. PARK ${ }^{2}$, R. BENNEWITZ ${ }^{1,3}$, A. CARON ${ }^{1,2, *}$ \\ ${ }^{1} N M$ - Leibniz Institute for New Materials, Campus D2.2, Saarbrücken 66123, Germany \\ ${ }^{2}$ KoreaTech, Korea University of Technology and Education, Chungnam Province 330-708, Republic of Korea \\ ${ }^{3}$ Department of Physics, Saarland University, Saarbrücken 66123, Germany \\ ${ }^{\dagger}$ Present address: Department of Materials Sciences and Engineering, Zhejiang University, Hangzhou 310058, China \\ Received: 31 October 2016 / Revised: 28 December 2016 / Accepted: 11 January 2017 \\ C The author(s) 2017. This article is published with open access at Springerlink.com
}

\begin{abstract}
Thermally grown surface oxide layers dominate the single-asperity tribological behavior of a $\mathrm{Zr}_{60} \mathrm{Cu}_{30} \mathrm{Al}_{10}$ glass. Increase in oxidation time leads to an increased contribution of shearing and a corresponding decreased contribution of ploughing to friction. This change in the dominating friction and wear mechanism results in an overall minor decrease of the friction coefficient of oxidized surfaces compared to the metallic glass sample with native surface oxide. Our results demonstrate the importance of creating a stable oxide layer for practical applications of metallic glasses in micro-devices involving sliding contact.
\end{abstract}

Keywords: metallic glasses; surface oxide; friction; wear; nanotribology; atomic force microscopy

\section{Introduction}

Metallic glasses are structurally amorphous metallic alloys whose compositions are designed to prevent crystallization upon cooling from the melt [1]. Owing to their low elastic moduli high hardness metallic glasses have been reported to provide low friction and low wear rates [2-4]. Studies comparing the macro-scale wear behavior of metallic glasses and their crystalline counter-parts or steel have reported ambiguous results. Kwon et al. [5] compared the wear behaviour of a Zr-based bulk metallic glass with hardened steel. While the friction coefficients of both materials were similar, the authors reported a significantly lower wear resistance for the Zr-based bulk metallic glass and discussed the difference of underlying wear mechanisms: brittle wear in the case of the Zr-based bulk metallic glass and adhesive wear in the case of the hardened steel. Tam and Shek reported a higher friction coefficient for metallic glasses than for their crystalline counterparts despite their higher mechanical strength and hardness [6], while Yoon et al. [7] observed an increase in hardness upon crystallization of a Ni-based metallic glass but also an increase in the friction coefficient and of the wear rate. No unique correlation between the hardness and the tribological behaviour of metallic glasses has been established so far. At the macro-scale the tribological mechanisms are complex and involve a combination of plasticity, structural relaxation and transformation [8], and material transfer [9], or mixing $[10,11]$ with subsequent chemical reactions and structural changes.

Meanwhile, metallic glasses have been recognized as potential materials for micro-electromechanical applications, such as micro-gears and media-storage devices $[12,13]$. This potential owes to their excellent thermoplastic formability down to the nm-scale within their undercooled liquid region [14]. For such applications, the tribological performance of metallic glasses at the nanometer scale is of crucial importance. Recently, some of the authors have investigated the nanoscopic friction and wear mechanisms of a Pt-based metallic glass surface in UHV after its native oxide

* Corresponding author: A. CARON, E-mail: arnaud.caron@koreatech.ac.kr 
removal in comparison to a $\mathrm{Pt}(111)$ surface [15]. We found that the wear-less friction coefficient was barely measurable on both surfaces with an inert diamond counter-body, while it significantly increased with a $\mathrm{SiO}_{x}$ counter-body. This observation demonstrates the effect of surface chemistry on tribological processes that may involve interfacial alloying. At the nanometer scale also, native and grown oxide surface films play an increasing role. A recent study has shown that the oxide layer on a Ni-based metallic glass enhances the wear resistance [16]. The tribological response of oxides is not unique and has been reported to differ depending on the bonding strength of oxygen with the metallic elements: a weaker bond was found to correspond to a higher friction coefficient [17].

In this work we use TEM, AFM, and XPS to characterize the structure and properties of oxide layers grown on amorphous $\mathrm{Zr}_{60} \mathrm{Cu}_{30} \mathrm{Al}_{10}$ ribbons by annealing in air at $504 \mathrm{~K}$ for $30 \mathrm{~min}$ and $60 \mathrm{~min}$ and we report and discuss the load dependence of friction for oxide layers of different thicknesses.

\section{Experimental methods and materials preparation}

$\mathrm{A} \mathrm{Zr}_{60} \mathrm{Cu}_{30} \mathrm{Al}_{10}$ master alloy was prepared by melting elemental $\mathrm{Zr}, \mathrm{Cu}$, and $\mathrm{Al}$ with a purity $>99.9 \mathrm{wt} . \%$ in the corresponding weight proportion by arc-melting in Zr-gettered Ar-atmosphere. The melting process was repeated three times to ensure homogeneous mixing of the elements. Subsequently, $0.2 \mathrm{~mm}$ thick $\mathrm{Zr}_{60} \mathrm{Cu}_{30} \mathrm{Al}_{10}$ metallic glassy ribbons were prepared by melt-spinning on a water-cooled $\mathrm{Cu}$-wheel, using Ar as an injection gas. The amorphous structure of the as-spun ribbons was confirmed by X-ray diffraction (XRD) with $K_{\mathrm{a}}$ radiation and differential scanning calorimetry (DSC). Further samples from the same batch have been oxidized in air at $T=504 \mathrm{~K}$ for $30 \mathrm{~min}$ and $60 \mathrm{~min}$. The temperature was selected well below the glass transition on-set temperature $T_{\mathrm{g} \text {, on-set }}=673 \mathrm{~K}$ in order to avoid structural relaxation of the metallic glass $[18,19]$. The surface composition and oxide layer thickness on as-spun and oxidized samples have been determined by X-ray photoemission spectroscopy (XPS) using a K-Alpha ${ }^{+}$XPS System, manufactured by ThermoFisher Scientific. In particular, the composition was determined from the peak area of the different elemental spectra and their bonding states were determined from the peak energy-shifts.

The effect of oxidation treatment in air on the surface topography was determined by tapping-mode AFM using a NanoWizard 3 Ultra AFM manufactured by JPK Instruments, Germany and a single crystalline $\mathrm{Si}$ cantilever (PPP-NCLR, NanoSensors, Germany). AFM scratching tests on as-spun and oxidized samples were performed at room temperature and in ambient conditions with a diamond-coated silicon cantilever (CDT-NCLR, NanoSensors, Switzerland). The normal and lateral spring constant of the cantilever, $k_{\mathrm{N}}$ and $k_{\mathrm{L}}$, were determined from the geometrical beam model according to $k_{\mathrm{N}}=\frac{E w t^{3}}{4 l^{3}}$ and $k_{\mathrm{L}}=\frac{G w t^{3}}{3 h^{2} l}$, where $E$ is Young's modulus, $G$ is the shear modulus. The width $w$, the length $l$, and the tip height $h$ were measured optically. The thickness of the cantilever was determined from the first bending resonance frequency of the cantilever $f_{0}$ according to $t=\frac{2 \sqrt{12} \pi}{1.875^{2}} \sqrt{\frac{\rho}{E}} f_{0} l^{2}$, where $\rho$ is the mass density. The sensitivity of the photodetector $S$ was determined by recording forcedistance curves, in which the slope of the repulsive part corresponds to $1 / S$. The normal and lateral forces were calculated from the vertical and lateral photodiode voltages by assuming the same photodiode sensitivity in both directions according to $F_{\mathrm{N}}=k_{\mathrm{N}} S V_{\mathrm{N}}$ and $F_{\mathrm{N}}=\frac{3}{2} k_{\mathrm{L}} \frac{h}{l} S V_{\mathrm{L}}$, where $V_{\mathrm{N}}$ and $V_{\mathrm{L}}$ are the vertical and lateral voltages of the photodiode, respectively. For the diamond-coated cantilever used in this work we found $k_{\mathrm{N}}=48 \mathrm{Nm}^{-1}$ and $k_{\mathrm{L}}=6643 \mathrm{Nm}^{-1}[20,21]$.

Single cycles of reciprocal scratch tests perpendicular to the cantilever axis were performed over a length $l_{\mathrm{s}}=300 \mathrm{~nm}$ at normal force $F_{\mathrm{N}}=500-7,000 \mathrm{nN}$, during which $F_{\mathrm{L}}$ was recorded. Wear scratches were imaged by tapping mode AFM to determine their width. The friction force was calculated according to $F_{\mathrm{f}}=\left(F_{\mathrm{L}, \text { trace }}-\right.$ $\left.F_{\mathrm{L} \text {,retrace }}\right) / 2$, where $F_{\mathrm{L} \text {,trace/retrace }}$ are the lateral forces recorded during the forward and backward sliding motion of the cantilever during reciprocal scratching, respectively. For all measurements, the sliding velocity was $v=600 \mathrm{~nm} / \mathrm{s}$. 
All results presented in this report are recorded with the same diamond-coated cantilever to directly compare the tribological performance of the different sample surfaces. All AFM-measurements were repeated twice with a different tip for each comparative series of measurements on the different samples. Given geometrical difference of the AFM-tips minor differences in the numerical values of the friction forces and the width of the scratches were observed but did not significantly affect the overall trend and the values of the friction coefficient and of the scratch hardness. This number of measurement repetition does not allow for statistical analysis. However, the authors would like to stress out the representative character of the measurements presented here. The significance of AFM-measurements relies on the idealization of a tribological contact between a smooth surface and a single asperity, i.e., the AFM-tip. For a given type of cantilevers, the geometry of the tips can be treated as equivalent, thanks to optimized production processes and controls of the manufacturers.

\section{Samples characterization}

The chemical composition of the oxide layers on the as-spun and the annealed samples is listed in Table 1.
The bonding state of the elements was determined from the peak energy-shift. Correspondingly, Table 1 also indicates the molecular fraction of the respective oxide compounds. We find that the oxide layer mostly consists of a $\mathrm{ZrO}_{2}$ and $\mathrm{Cu}_{2} \mathrm{O}$. After oxidation treatment, an increase in oxygen concentration was measured. This increase in oxygen concentration is attributed to a departure from stochiometry for $\mathrm{ZrO}_{2}$ and $\mathrm{Cu}_{2} \mathrm{O}$. Both these oxides have a wide concentration range for oxygen. Increasing the oxidation time resulted in an increase in the $\mathrm{Cu}_{2} \mathrm{O}$ molar fraction. Recently, Louzguine-Luzgin et al. have investigated the structure and growth rate of the native oxide on a $\mathrm{Cu}_{47} \mathrm{Zr}_{45} \mathrm{Al}_{8}$ bulk metallic glass [22]. They found that after several days of exposition to ambient air the oxide layer mostly consisted of $\mathrm{Zr}_{2} \mathrm{O}$ and $\mathrm{Cu}_{2} \mathrm{O}$, and a minor amount of $\mathrm{Al}_{2} \mathrm{O}_{3}$. The chemical composition of the metallic glass investigated in Ref. [22] is comparable to the one of the metallic glass investigated in this work and we expectedly find our results in good agreement with the results by Louzguine-Luzgin et al.

Figure 1 shows high-resolution TEM images on the cross section of a sample oxidized for $90 \mathrm{~min}$. Both high resolution TEM images show that the structure of the underlying metallic alloy was amorphous after the oxidation treatment. However, crystallized regions

Table 1 Atomic elemental concentration of the oxide layer as a function of annealing time in air at $504 \mathrm{~K}$. Also indicated are the corresponding molar fraction of oxide compounds.

\begin{tabular}{cccccccc}
\hline & $\mathrm{O}$ & $\mathrm{Al}$ & $\mathrm{Zr}$ & $\mathrm{Cu}$ & $\mathrm{ZrO}_{2}$ & $\mathrm{Cu}_{2} \mathrm{O}$ & $\mathrm{Al}_{2} \mathrm{O}_{3}$ \\
\hline As-spun & 60.35 & 0.86 & 31.53 & 7.25 & 88.60 & 10.19 & 1.21 \\
30min & 75.56 & 1.06 & 18.87 & 4.50 & 87.15 & 10.40 & 2.45 \\
$60 \mathrm{~min}$ & 72.57 & 0.93 & 18.19 & 8.30 & 79.76 & 18.19 & 2.03 \\
\hline
\end{tabular}

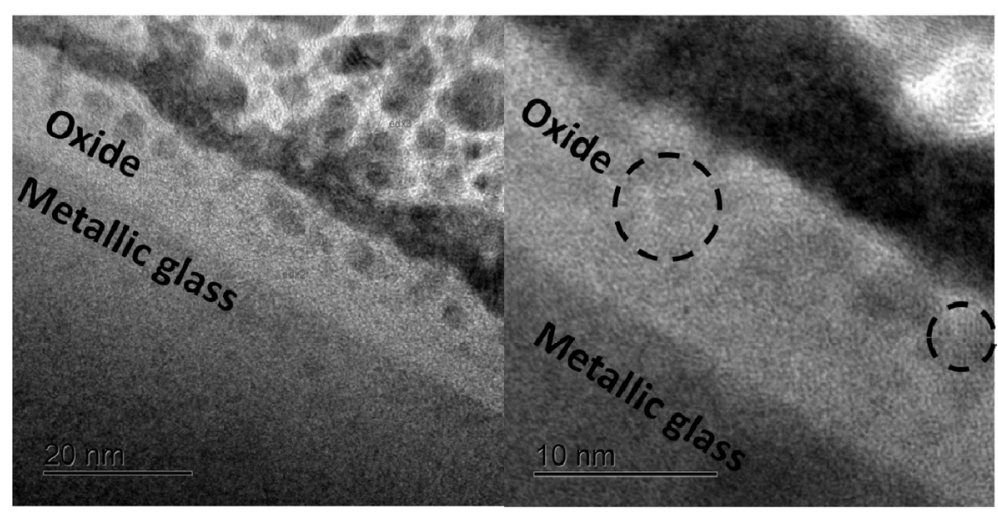

Fig. 1 Cross-sectional HRTEM images of a $\mathrm{Zr}_{60} \mathrm{Cu}_{30} \mathrm{Al}_{10}$ metallic glass sample annealed for 90 min in air at $504 \mathrm{~K}$. The doted circles inserted in the higher magnification micrograph (right) indicate crystalline domains. 
of a few $\mathrm{nm}$ in diameter are observed in the oxide layer; for this sample the thickness of the oxide layer was found to be $t_{\text {oxide, } 90 \mathrm{~min}}=10 \mathrm{~nm}$. In Ref. [22], Louzguine-Luzgin et al. reported on the occurrence of $\mathrm{Cu}_{2} \mathrm{O}$ nanoparticles of $\sim 10 \mathrm{~nm}$ in size within a Zr-rich amorphous oxide matrix. There, the authors identified the nanocrystalline particles based on the spacing between the lattice fringes. For selected particles, they measured $213 \mathrm{pm}$, corresponding to the interplanar distance of $\{200\}$-planes in $\mathrm{Cu}_{2} \mathrm{O}$. In this work though, the contrast of the TEM image is to shallow to measure the spacing of the lattice fringe with accuracy. This is partly due to the fact that the TEM sample was too thick. Thus, the lattice fringes of the crystallites are overlaid with the amorphous structure of the matrix.

Figure 2 shows topography images recorded by tapping-mode AFM. The RMS roughness was between $50 \mathrm{pm}$ and $80 \mathrm{pm}$. The results confirm the impressive flatness of melt-spun metallic glass ribbons, whose roughness is almost at the limit of the sensitivity of AFM experiments. It is found that the oxidation treatments did not affect the surface roughness of the samples.
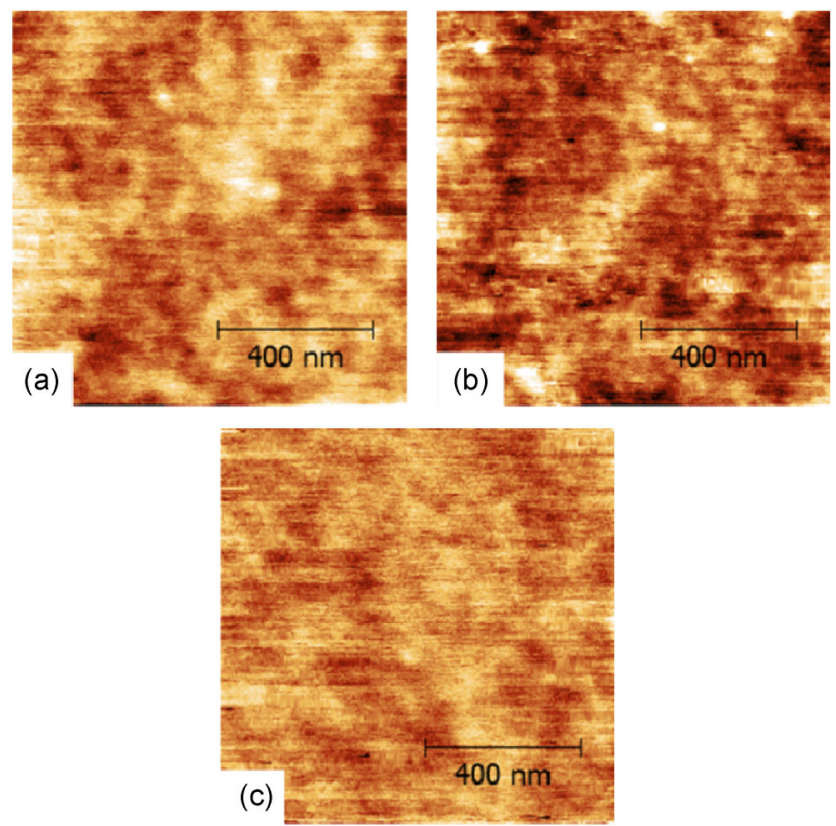

Fig. 2 Topography images recorded by tapping mode AFM on $\mathrm{Zr}_{60} \mathrm{Cu}_{30} \mathrm{Al}_{10}$ metallic glass surface (a) in the as-spun state and after controlled oxidation treatment at $504 \mathrm{~K}$ for (b) $30 \mathrm{~min}$ and (c) $60 \mathrm{~min}$. In all three images the $z$-scale is $500 \mathrm{pm}$. The root mean square roughness values corresponding to the topography images are (a) $71 \mathrm{pm}$, (b) $79 \mathrm{pm}$, and (c) $53 \mathrm{pm}$.

\section{Results}

Figure 3 shows topography images of the as-spun $\mathrm{Zr}_{60} \mathrm{Cu}_{30} \mathrm{Al}_{10}$ sample after scratch tests with normal forces ranging from $F_{\mathrm{N}}=0.9 \mu \mathrm{N}$ to $F_{\mathrm{N}}=4.7 \mu \mathrm{N}$. For normal force $F_{\mathrm{N}}<2 \mu \mathrm{N}$, no remaining scratches could be distinguished. In this work, the projected area of contact $A_{\mathrm{c}}$ was determined from the width $W_{\mathrm{s}}$ of the remaining scratch according to $A_{c}=\frac{\pi W_{s}^{2}}{4}$. The scratch hardness $H$ was determined as the inverse slope of the contact area plotted versus the normal load, i.e., $\frac{1}{H}=\frac{\mathrm{d} A_{\mathrm{c}}}{\mathrm{d} F_{\mathrm{N}}}$ or $H=\frac{\mathrm{d} F_{\mathrm{N}}}{\mathrm{d} A_{\mathrm{c}}}$. According to Bowden and Tabor [23], two mechanisms contribute to friction, the shearing of asperity junctions and ploughing. The friction force can be expressed as $F_{\mathrm{f}}=\tau A_{\mathrm{c}}+\mu_{\mathrm{p}} F_{\mathrm{N}}$, where $\tau$ is the shear strength and $\mu_{\mathrm{p}}$ is the friction coefficient associated with ploughing. To decouple the shearing term from the ploughing term, the friction force has been expressed as $F_{\mathrm{f}}=\tau A_{\mathrm{c}}+H A_{f}=\left(\mu_{\mathrm{s}}+\right.$ $\left.\mu_{\mathrm{p}}\right) F_{\mathrm{N}}$, where $A_{\mathrm{f}}$ is the projected area between the submerged part of the indenter and the scratch front [23] and $\mu_{\mathrm{s}}$ is the friction coefficient associated to
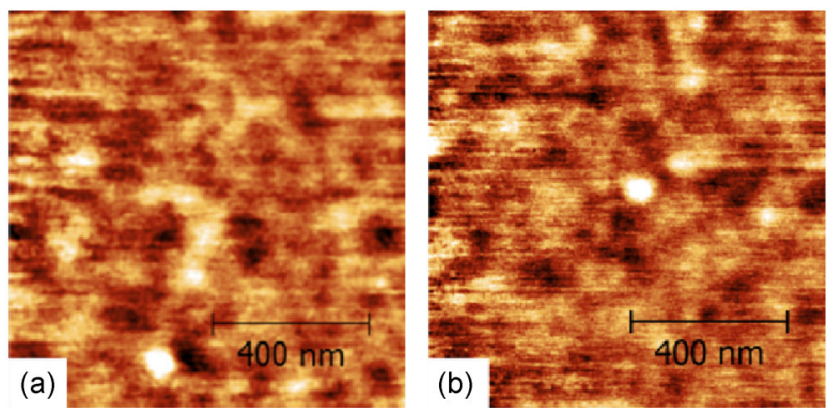

(b)
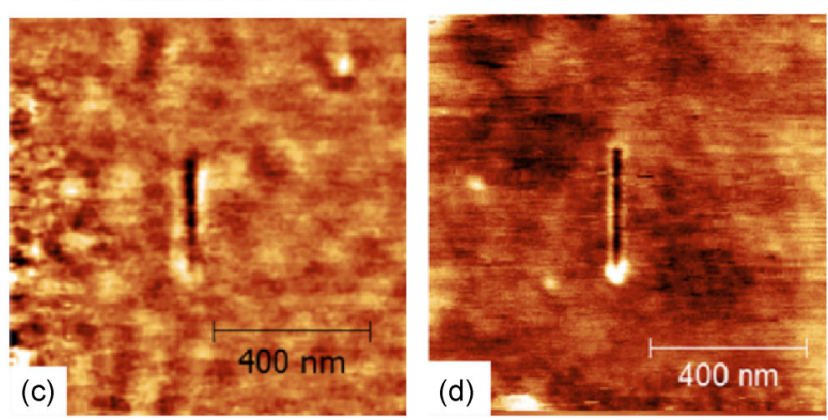

Fig. 3 Topography after scratch tests over a length $l_{\mathrm{s}}=300 \mathrm{~nm}$ at the normal forces $F_{\mathrm{N}}$ : (a) $0.9 \mu \mathrm{N}$, (b) $1.9 \mu \mathrm{N}$, (c) $2.8 \mu \mathrm{N}$, and (d) $3.8 \mu \mathrm{N}$. 
shearing. While $A_{\mathrm{c}}$ and $H$ can be readily determined from the experimental results, the evaluation of $\tau$ and $A_{\mathrm{f}}$ is not straightforward. In principle, $A_{\mathrm{c}}$ and $A_{\mathrm{f}}$ are interdependent on $W_{\mathrm{s}}$. For a spherical indenter $A_{\mathrm{f}}$ is approximately given by $A_{\mathrm{f}}=\frac{1}{12} \frac{W_{s}^{3}}{R}$, where $R$ is the radius of the spherical indenter.

In the wear-less regime though, the ploughing contribution can be excluded and the shearing friction coefficient $\mu_{\mathrm{s}}$ can be determined from the linear slope of the friction force plotted against the normal load. In the wear regime, the linear slope of the friction force corresponds to the superposed effects of shearing and ploughing, in this case we can write $\frac{\mathrm{d} F_{\mathrm{f}}}{\mathrm{d} F_{\mathrm{N}}}=\mu_{\mathrm{s}}+$ $\mu_{\mathrm{p}}=\mu$, where $\mu$ is the total friction coefficient.

Figure 4(a) shows the load dependence of the friction force for the three samples investigated. For all samples remaining scratches, i.e., wear, were observed for $F_{\mathrm{N}} \geqslant 2.4 \mu \mathrm{N}$. We observe for all three samples that the slope $\frac{\mathrm{d} F_{\mathrm{f}}}{\mathrm{d} F_{\mathrm{N}}}$ becomes steeper in the wear regime. This effect is more pronounced for the as-spun sample and
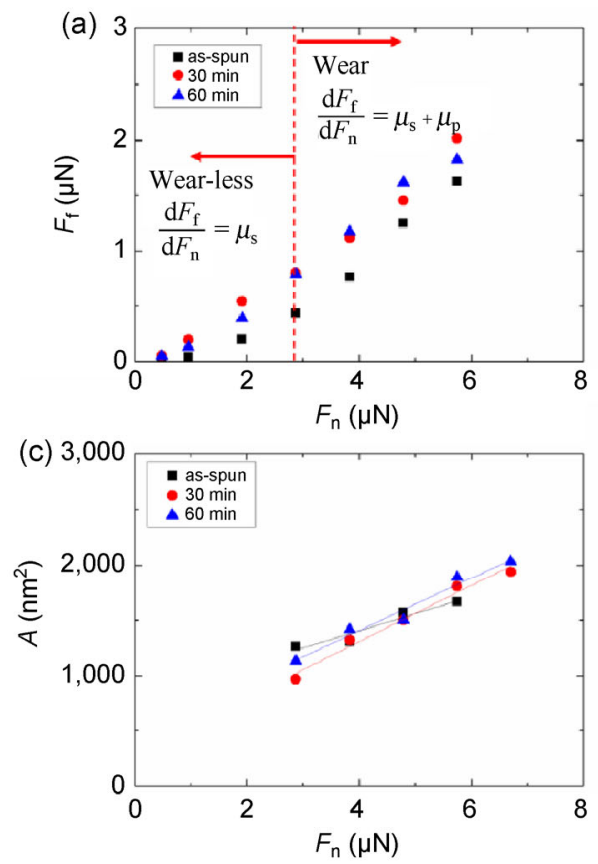

less pronounced with increasing oxidation time. The friction force measured on the as-spun sample was slightly higher than on the oxidized samples over the whole range of normal forces, while it was very similar on both oxidized surfaces. The respective friction coefficient for shearing and ploughing, $\mu_{\mathrm{s}}$ and $\mu_{\mathrm{p}}$, were determined as described above and are shown in Fig. 4(b). The values of the shearing friction coefficient $\mu_{\mathrm{s}}$ increase from 0.177 for the as-spun sample to 0.315 and 0.309 for the samples oxidized for $30 \mathrm{~min}$ and $60 \mathrm{~min}$, respectively. The values of the ploughing friction coefficient $\mu_{\mathrm{p}}$ decrease from 0.246 for the as-spun sample to 0.102 and 0.059 for the samples oxidized for $30 \mathrm{~min}$ and $60 \mathrm{~min}$, respectively. In the wear regime, the total friction coefficient thus changes from 0.423 for the as-spun sample to 0.417 and 0.368 for the samples oxidized for $30 \mathrm{~min}$ and $60 \mathrm{~min}$, respectively. The value for $H_{\mathrm{s}}=6.67 \mathrm{GPa}$ for the as-spun sample (see Fig. 4(d)) is 1.7 times higher than those of the values for the oxidized samples of $3.95 \mathrm{GPa}$ and $4.12 \mathrm{GPa}$. A clear tendency can be recognized: the surface of the investigated metallic glass mechanically softens upon oxidation. With
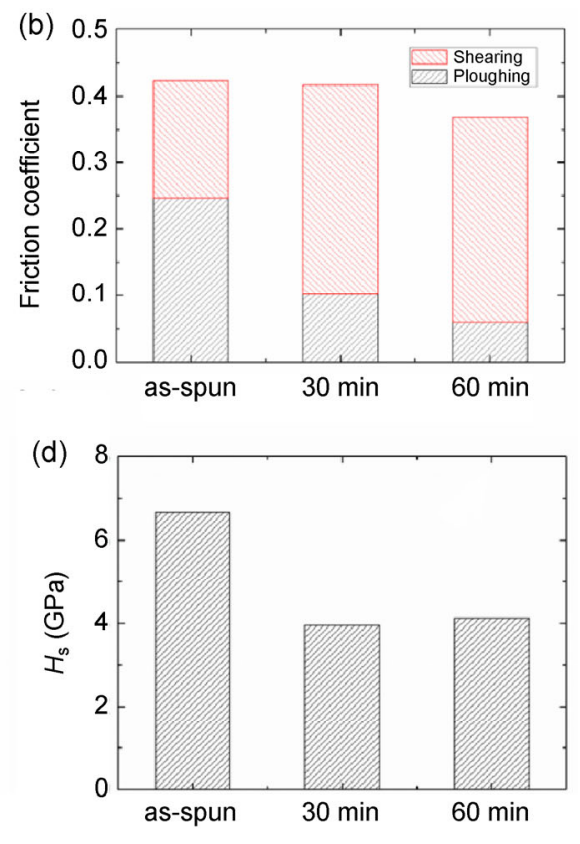

Fig. 4 (a) Friction force as a function of normal force for the as-spun and metallic glass surfaces oxidized for 30 min and 60 min. The division in wear-less and wear regime is based on the AFM results; (b) comparison of friction coefficients; (c) projected contact area as a function of the normal force; and (d) comparison of the scratch hardness. 
increasing oxidation time, the contribution of ploughing to friction decreases. This observation can be explained by considering that in the case of ploughing friction forces arise from the resistance of the surface material to displacement ahead and aside of the indenter. As the hardness of a material describes its resistance to plastic flow, the effect of ploughing on friction becomes smaller for a softer surface. Moreover, the increased contribution of shearing to friction with oxidation time indicates an increased adhesion and possible material transfer.

\section{Discussion}

The XPS and TEM results show that thickness of the oxide layer on $\mathrm{Zr}_{60} \mathrm{Cu}_{30} \mathrm{Al}_{10}$ increased up to $10 \mathrm{~nm}$ upon annealing in air at $504 \mathrm{~K}$ for $90 \mathrm{~min}$. For all samples, the surface oxide was found to mostly consist in a mixture of $\mathrm{Zr}$ and $\mathrm{Cu}$ oxides. From the topography images shown in Fig. 2 with roughness lower than $1 \mathrm{~nm}$ we conclude that the effect of the oxidation treatment on the geometrical surface parameters can be neglected. While the effect of the surface oxidation treatment on the friction coefficient was small, our results demonstrate that the presence of a thermally grown surface oxide layer changes the governing mechanism for friction and wear. After growth of a surface oxide the contribution of ploughing to the friction coefficient decreased from $58 \%$ for the as-spun sample to $25 \%$ and $16 \%$ for the samples oxidized for $30 \mathrm{~min}$ and $60 \mathrm{~min}$, respectively. In the later cases wear was dominated by shearing. It is interesting to note that the change in the governing mechanism for friction and wear was accompanied by a surface softening as illustrated in Fig. 5(d) by the decrease in $H_{\mathrm{s}}$. Based on these observations we attribute the ploughing contribution to friction and wear to the plastic deformation of the metallic glass below the native or thermally grown surface oxide layer. On the other hand, shearing is attributed to adhesion of the surface oxide to the indenter. This is in line with the observation that the pile-ups on the sides and the ends of the scratches shown in Figs. 3(c) and 3(d) are much less prominent than those observed in our previous study on metallic glass surfaces in UHV conditions after oxide removal [16]. In a recent work, Louzguine-Luzgin et al. characterized the nano-scale wear of three different metallic glasses with a native surface oxide layer [24]. The authors estimated the wear rate from the scratched volume normalized by the length of the scratch performed with a sharper single crystalline diamond tip than the polycrystalline diamond coated tip used in this work. Owing to the sharpness of the tip used in Ref. [24] wear set at lower load values than in this work and the ploughing contribution is expected to be higher. Nevertheless, it is interesting to note that the authors observed a change of wear regime when the scratch depth became larger than the thickness of the native surface oxide layer. The specific wear rate became much larger when scratching deeper than the oxide layer. Though not explicitly mentioned in their work, we suggest that this corresponds to a transition from adhesive to abrasive wear. Classically, the unit less abrasive wear constant $k_{\mathrm{abr}}=10^{-3}-10^{-1}$ and for adhesive wear $k_{\mathrm{adh}}=$ $10^{-6}-10^{-4}$ (see Ref. [25] for more details).

Furthermore, our experimental values for $\mu$ are lower than those found in macro-scale experiments, where the friction coefficients in the range of $\mu=0.3-$ 0.7 have been reported. The discrepancy can be explained by the absence of major plastic deformation in friction of oxide layers, which is however inherent to macro-scale friction experiments.

The tribology of $\mathrm{ZrO}_{2}$ has been a topic of intensive research (see for example Refs. [26-28]). Recently, the low friction and wear of $\mathrm{ZrO}_{2}$ thin layers on steel have been connected to the stress-induced martensitic transformation from tetragonal to monoclinic zirconia [26]. In our experiments, the surface oxide layer was found to be partially crystalline. The structure of the nanocrystals was not identified so that a pressure or shear induced martensitic transformation of oxide nano-grains can only be suggested as a hypothesis. Our results on the favorable tribological response of mixed $\mathrm{Zr}$ and $\mathrm{Cu}$ oxides may shed light on previous results obtained on $\mathrm{CuO}$ doped $\mathrm{Y}$-stabilized $\mathrm{ZrO}_{2}$ by pin-on-disc and AFM experiments, where an interfacial layer with low shear strength generated in the early stage of sliding friction tests has been invoked to explain reduced wear and friction [28]. 


\section{Conclusions}

The contribution of surface oxide layers to the singleasperity tribological response of a $\mathrm{Zr}_{60} \mathrm{Cu}_{30} \mathrm{Al}_{10}$ glass increases significantly upon annealing. The thermal growth of the oxide layer leads to a decrease of scratch hardness. Shearing mediated by adhesion becomes the governing mechanism of friction and wear while ploughing related to plastic deformation of the underlying metallic glass becomes less important. The results clearly demonstrate the dominant role of the oxide layer in frictional microscopic contacts with metallic glasses and the importance of creating a stable oxide layer for practical applications in micro-devices involving sliding contact.

\section{Acknowledgement}

S. J. K., A. C. and, R. B. are grateful to Prof. E. Arzt for his continuous interest and support of this work. A. C. and S. J. K. were supported by the German Science Foundation (DFG). The authors thank Dr. M. Koch (INM) for his support by providing high-resolution TEM results.

Open Access: The articles published in this journal are distributed under the terms of the Creative Commons Attribution 4.0 International License (http:// creativecommons.org/licenses/by/4.0/), which permits unrestricted use, distribution, and reproduction in any medium, provided you give appropriate credit to the original author(s) and the source, provide a link to the Creative Commons license, and indicate if changes were made.

\section{References}

[1] Inoue A. Stabilization of metallic supercooled liquid and bulk amorphous alloys. Acta Mater 48(1): 279-306 (2000)

[2] Imura T, Hasegawa K, Moori M, Nishiwaki T, Takagi M, Kawamura Y. Cyclic deformation and tribological behavior of an amorphous iron-based alloy film. Mater Sci Eng A 133(1): 332-336 (1991)

[3] Morris D G. The properties of dynamically compacted Metglas ${ }^{\circledR}$ 2826. J Mater Sci 17(6): 1789-1794 (1982)

[4] Lee D E, Evett J E. Sliding friction and structural relaxation of metallic glasses. Acta Metall 32(7): 1035-1043 (1984)
[5] Kwon D H, Lee K M, Park E S, Kim H J, Bae J C, Huh M Y. Wear behaviors of bulk metallic glass alloy and hardened steel having the same hardness value. J Alloys Comp 536S: S99-S102 (2012)

[6] Tam C Y, Shek C H. Abrasive wear of $\mathrm{Cu}_{60} \mathrm{Zr}_{30} \mathrm{Ti}_{10}$ bulk metallic glass. Mater Sci Eng A 384(1-2): 138-142 (2004)

[7] Yoon S, Lee C, Choi H. Evaluation of the effects of the crystallinity of kinetically sprayed Ni-Ti-Zr-Si-Sn bulk metallic glass on the scratch response. Mat Sci Eng A 449-551: 285-289 (2007)

[8] Boswell PG. The wear resistance of liquid quenched metallic glass. J Mater Sci 14(6): 1505-1507 (1979)

[9] Kishore U S, Chandran N, Chattopadhyay K. On the wear mechanism of iron and nickel based transition metal-metalloid metallic glasses. Acta Metall 35(7): 1463-1473 (1987)

[10] Fu X-Y, Kasai T, Falk M L, Rigney D A. Sliding behavior of metallic glass: Part I. Experimental investigations. Wear 250(1-2): 409-419 (2001)

[11] Fu X-Y, Kasai T, Falk M L, Rigney D A. Sliding behaior of metallic glass: Part II. Computer simulations. Wear 250(1-2): 420-430 (2001)

[12] Ishida M, Takeda H, Watanabe D, Amiya K, Nishiyama N, Kita K, Saotome Y, Inoue A. Fillability and imprintability of high-strength Ni-based bulk metallic glass prepared by the precision die-casting technique. Mater Trans 45(4): 1239-1244 (2004)

[13] Sharma P, Zhang W, Amiya K, Kimura H, Inoue A. Nanoscale patterning of $\mathrm{Zr}-\mathrm{Al}-\mathrm{Cu}-\mathrm{Ni}$ metallic glass thin films deposited by magnetron sputtering. J Nanosci Nanotechnol 5(3): 420-424 (2005).

[14] Schroers J. Processing of bulk metallic glass. Adv Mater 22(14): 1566-1597 (2010)

[15] Caron A, Sharma P, Shluger A, Fecht H-J, LouzguineLuzguin D V, Inoue A. Effect of surface oxidation on the nm-scale wear behavior of a metallic glass. J Appl Phys 109(8): 083515 (2011)

[16] Caron A, Louzguine-Luzguin D V, Bennewitz R. Structure vs chemistry: Friction and wear of Pt-based metallic surfaces. ACS Appl Mater Interf 5(21): 11341-11347 (2013)

[17] Suzuki S, Osaki H, Ando E. Materialistic difference in macroscopic friction coefficients of sputtered oxide thin films deposited on glass. Jpn J Appl Phys 35(3): 1862-1867 (1996)

[18] Wang D, Tan H, Li Y. Multiple maxima of GFA in three adjacent eutectics in $\mathrm{Zr}$-Cu-Al alloy system-A metallographic way t pinpont the best glass forming alloys. Acta Mater 53(10): 2969-2979 (2005)

[19] Inoue A, Negishi T, Kimura H M, Zhang T, Yavari A R. Mater Trans 39(2): 318-321 (1998) 
[20] Meyer E, Overney R M, Dransfeld K, Gyalog T. Friction and Rheology on the Nanometer Scale. Singapore: World Scientific, 1998.

[21] Caron A, Qin C L, Gu L, González S, ShlugerA, Fecht H-J, Louzguine-Luzguin D V, Inoue A. Structure and nanomechanical characterisitcs of surface oxide ayers on a metallic glass. Nanotechnology 22(9): 095704 (2011)

[22] Louzguine-Luzgin D V, Chen C L, Lin L Y, Wang Z C, Ketov S V, Miyama M J, Trifonov A S, Lubenchenko A V, Ikuhara Y. Bulk metallic glass surface native oxide: Its atomic structure, growth rate and electrical properties. Acta Mater 97: 282-290 (2015)

[23] Bowden FP, Tabor D. The Friction and Lubrication of Solids. Oxford (UK): Oxford University Press, 1950.

[24] Louzguine-Luzgin D V, Nguyen H K, Nakajima K, Ketov S V, Trifonov A S. A study of the nanscale and atomic

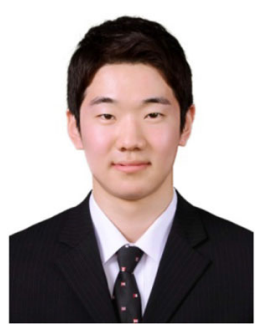

S. J. KANG. He received his bachelor degree in material science and engineering from Koreatech (Korea University of Technology and Education), Cheonan, Korea. During his bachelor program, he has done an internship program as

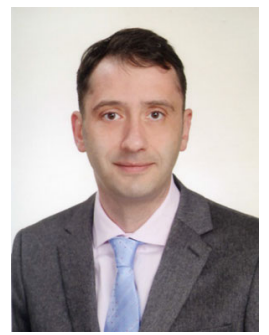

A. CARON. He is a materials scientist with expertise in the multi-scale mechanical behavior of materials, surfaces and microcomponents. Since 2015 Arnaud Caron is assistant professor in the School of Energy, Materials and Chemical Engineering at KoreaTech-Korea University of Technology and Education, Republic of Korea. Arnaud Caron obtained his engineering degree in scale wear resistance of metallic glasses. Materials Lett 185: 54-58 (2016)

[25] Rabinowicz E. Friction and Wear of Materials, $2^{\text {nd }}$ Edition. New York (USA): John Wiley \& Sons Inc., 1995.

[26] Zhang W, Ji G, Bu A, Zhang B. Tailoring the valence band offset of $\mathrm{Al}_{2} \mathrm{O}_{3}$ on epitaxial $\mathrm{GaAs}_{1-\mathrm{y}} \mathrm{Sb}_{\mathrm{y}}$ with tunable antimony composition. ACS Appl Mat Interf 7(51): 28624-28631 (2015)

[27] Tocha E, Schoenherr H, Vansco G J. Influence of grain size and humidity on the nanotribological properties of wearresistant nanostructured $\mathrm{ZrO}_{2}$ coating: An atomic force microscopy study. J Am Ceram Soc 88(9): 2498-2503 (2005)

[28] Tocha E, Pasaribu H R, Schipper D J, Schoenherr H, Vansco G J. Low friction in CuO-dopped yttria-stabilized tetragonal zirconia ceramics: A complementary macro- and nanotribology study. J Am Ceram Soc 91(5): 1646-1652 (2008)

an assistant researcher in Nano-tribology group at INM-Leibniz Institute for New Materials, Saarbrücken, Germany. He is studying for his master degree in material science and engineering at Zhejiang University. His research interests include new-structured materials, nano-tribology and mechanical properties of metallic glasses.

materials science in 2004 from the University of Saarland, Germany and was awarded with the Schiebold Medal. In 2009 he earned his doctoral degree in materials science from the University of Saarland, Germany. From 2007 to 2015 Arnaud Caron worked as a research associate at the Institute of micro- and nanomaterials of the University of Ulm, Germany, the WPI-Advanced Institute of Materials Research, Japan and the Leibniz-Institute for New Materials, Germany. 